\title{
A cross-cultural study of the implementation of microcomputers into schools
}

\author{
Marilyn Fleer \\ Canberra College of Advanced Education
}

There is a strong commitment by education authorities for computer technology to become part of the curriculum in most Australian schools, however, little research has been focussed on how this will happen.

Many schools and education systems have had to rely on a trial and error method of implementation, resulting in a limited awareness of, and consideration for the:

\begin{abstract}
...issues of equal opportunity or disadvantage. In fact, many of them (school staff) did not recognize a need for any special provision to address

disadvantage due to gender, ethnicity, race or physical or mental handicap,

(Jennings and Bradley, 1984, p.10).
\end{abstract}

The findings of this broad based review of Western Australian computing programmes was possibly an indication of general trends Australia wide. In 1985 the National Advisory Committee in Computers in Schools recommended that:

\footnotetext{
...planning committees will need to make special provision to encourage access to the program by groups such as girls, aboriginals, disadvantaged students and the disabled, (1985, p. 29).
}

It appears that only limited research is available to guide these committees on the identification of the special provisions needed to encourage access to the programme by these special groups. Given the cross-cultural context many educationalist work in, and the implications this holds for Aboriginal schools children, research into computer education for Aborigines is urgently needed. 
This paper presents the research findings of a study which collected data on school and community perceptions about the introduction of computer technology and the implementation of computer education into six Western Australian Government schools with substantial Aboriginal enrolments. A significant number of factors were found to influence the take-up of the technology by individuals in schools. These factors, although focusing on Aboriginal education, were relevant to most school contexts and implementation plans for innovation.

\section{The study}

A multi-method research design, framed predominantly within the ethnographic tradition of participant observation, was employed. The study involved six schools for a period of 12 months, spread over two school years. In conjunction with the Education Department of Western Australia, four school settings (including staff, students and community) were selected to be representative of one of the four Aboriginal communities classified by the National Aboriginal Education Committee (NAEC) (see Willmot in Menary, 1981), - traditional, rural community, urban community and urban dispersed groups. The process of computer implementation at these four sites would be closely monitored, with extended assistance provided (group A schools: One Arm Point, Midvale, Geraldton, Onslow). A further two sites were chosen, from the NAEC "traditional" and "rural" categories, but these two schools would receive only the minimum assistance provided by the Education Department of Western Australia (group B schools: Warburton; Halls Creek).

Each school received a BBC model B Acorn microcomputer system, printer and word processor (Edword chip). Group B schools were supplied with the full range of educational software developed by the Ministry of Education (Wesoft) and some commercial software (e.g. Granny's Garden). School based in-servicing and ongoing support was offered to group B schools. Essentially four schools received support and resources simulating the best possible scenario with the remaining two schools being provided with minimal assistance illustrating the least desirable scenario.

This study sought to examine what factors, as seen from school and community perspectives, were involved in the introduction of computer technology and the implementation of computer education in selected Western Australian Government schools with Aboriginal students. It was intended that the results of the study could contribute to improvement of school practices by minimizing future implementation difficulties in similar school contexts, and enhance benefits for both Aboriginal students and the Aboriginal communities served by the schools. 


\section{Findings}

During the implementation of computer education in the six schools, many factors influenced the utilization of the technology by the schools. The main determinants affecting implementation included: the staff's perceptions of computer education; the support structures established within the school to afford its introduction; environmental constraints; the issue of suitable software; and the provision for continuity of the established programme.

These factors had a significant impact upon the teaching strategies employed, the community's perception of computer education for their students, and student responses to computer education as will be discussed in this paper.

The findings presented have been drawn from data collected in Aboriginal schools. However, these indicators suggest implementation problems which may occur in other schools, and could possibly be applicable to the implementation of computer education in many schools in Western Australia.

\section{Staff perceptions of computer education}

Pre-service preparation of teachers

The school staffs' perceptions about computer technology were influenced by their prior experience and any in-service training they had received before, or during, the introduction of the computers.

Most of the remote schools in the study (Halls Creek, Warburton, Onslow, Rangeway) had a predominance of staff members with less than two years of teaching experience, a feature common to many Aboriginal schools (Education Department of WA, 1986). Most of the teachers interviewed held the view that their teacher training did not include sufficient coverage of skills development in computer education. Most reported that their own computer education was developed through either mathematics or elective courses. The electives had been extremely popular, with insufficient places to meet the demand, resulting in most trainee teachers not being given the opportunity to develop computing skills. For those who successfully secured a place in such classes, two reactions were reported: first, an extremely negative perception of their own ability to use computers (resulting from courses which emphasized computer programming) and, secondly, too brief overviews of many software packages, and limited opportunities to consolidate what was learned. The limited opportunities for becoming computer literate during pre-service training put these teachers at a distinct disadvantage when faced with computers in their first teaching position. 
Graduate teachers were too busy adjusting to work and consolidating their teaching skills, often in a remote school with limited opportunities for support (as most teachers on staff are generally new graduates), to put effort into learning how to operate a computer or to familiarize themselves with software. Such remote schools were usually guided by a newly promoted Principal who was also busy consolidating managerial and administrative skills.

Hence, graduate teachers were less prepared than experienced teachers to take on the challenge of implementing the computer into their classroom. Experienced teachers were generally found to have had little exposure to computers, and had no knowledge of how to operate them. However, where a location is desirable, proportionately more experienced staff reside and remain for longer periods of time. In Rangeway and Midvale, experienced staff made efforts to learn about computers and pass their knowledge onto their colleagues. Efforts by experienced staff, combined with the tendency of staff to stay longer in a more desirable school, gradually developed the computer skills in the school and resulted in a slow but steady implementation.

The need for in-service training

In most of the schools, the introduction of the computer was met with apprehension, because of teachers' limited computer skills, and so the computer was generally not used. Those schools which received inservicing (schools with extended assistance - group A) showed significantly higher utilization of computers in the classroom. Where inservicing was inadequate, for example where junior primary teachers were shown upper primary software only, or where in-servicing did not occur (schools with limited assistance - group B), the computer was not adequately used.

The data showed that most teachers in these schools lacked computer literacy and needed some form of appropriate in-service training before they would contemplate using the computer. Generally, those teachers in schools which received extended assistance (group A), and who had some prior training in this area, adapted to using the computer more readily than those with no experience.

The provision of ongoing support after the initial school-based inservicing significantly increased the likelihood of staff making use of computers. When operational problems were dealt with immediately (by telephone or a subsequent visit by the researcher), frustration was greatly reduced. However, where such support was not readily available (group B schools - limited assistance), the frustration led staff to discontinue their use of the computer. 
The Principal's involvement

Within each of the schools, implementation was severely hampered when the Principal was not involved in the in-servicing. The Principal was the key element in sanctioning the use of the computers in classrooms. Where she or he did not fully support the use of computers, or had conflicting views about their use, staff use was significantly diminished. Procedural obstacles or maintenance problems of the computer education programme required either intervention by the Principal or the sanctioning of new structures. Where the Principal was not involved, implementation was slow, and in some cases made substantially more difficult.

\section{Support structures within the school}

The support structures created within a school, or their absence, during the course of implementation influenced the overall taking up of the technology by individual staff members. The different support structures developed in schools, and their success or failure for implementation, are discussed in this section.

Most schools appointed a computer co-ordinator to be responsible for the hardware and the software. The co-ordinator's position was assumed as an extra task by a teacher, the Principal or the Aboriginal Education Worker (AEW) in the school. Where this person was not only the co-ordinator but also a practising classroom teacher, many problems arose.

When staff had difficulties with either the hardware or the software during class time, they could not readily call upon the co-ordinator for help, as that person's teaching programme would be disrupted. As a result, the computer activities planned by the teacher were often aborted, leaving students and staff feeling equally frustrated. This reduced the effectiveness of computer use and limited student access, ultimately hindering implementation.

Similarly, where the Principal took charge of the programme implementation difficulties occurred. The Principals were generally in great demand by staff, parents or visitors to the school and resulting in time constraints. Teachers were less willing to approach the busy Principal for minor difficulties and in preference stopped their planned computer activities.

The most successful plan for the implementation of computer education into the school happened where the AEWs were involved. In Onslow, one of the AEWs was appointed as the computer co-ordinator. It was possible for the AEW to be freed at almost any time to assist with minor or major difficulties that teachers had with either the hardware or the software. This in turn ensured continued use of the computer with students. In addition, 
the AEWs, as part of their brief, work with teachers and therefore, the computer related activities were conducted either by the AEW or the teacher, in a team effort in the classroom. With the AEW aiding teachers in using the computer in their classroom, implementation happened quickly. Management concerns were easily overcome through the use of the AEW.

The AEW also in-serviced new staff members. The computer-based inservicing was achieved through demonstrations with students or during teachers' non-contact time, thus continuing the computer programme already established in the school, and ensuring continuing student access.

Similar success was reported in Rangeway school. Implementation difficulties were overcome through a multi-level support structure within the school. General support was provided by the teacher librarian, who reviewed and purchased software. He in turn encouraged the use of the equipment by pointing out new or suitable software to teachers when they entered the library seeking resources. The second level of support was provided by the senior assistant of each sub-school (junior primary, middle primary and senior primary). The Principal placed the responsibility for computer education with each senior assistant, who attended in-servicing and in turn in-serviced new or inexperienced users in her or his sub-school. In this way, teachers had a source of support close to their classrooms.

The third level of support occurred within the classrooms. At the grass roots level, the AEWs and teacher aides were shown how to use the hardware and appropriate software. The AEWs took responsibility for using the computer with students in much the same capacity as did teachers without AEWs. The teachers and AEWs made use of the computer to support the existing curriculum.

\section{Environmental constraints on implementation}

Mobility of equipment within the schools

Of greatest significance to the implementation of computer education in the schools, were the difficulties associated with the movement of computer equipment from one room to the next. Mobility problems arose because many schools in the study, particularly the remote schools, were made up of transportable buildings which had stairs at the entrance to each room. In most schools, a trolley was purchased to hold the computer. However, the total weight of the computer components made movement up and down stairs formidable. This difficulty resulted in the teachers, who were located within transportable buildings, making less and less use of the computer which ultimately resulted in inequitable access to it by their students. 
Remoteness

The remoteness of some schools in the study significantly impeded the computer programme. Such schools as Warburton, One Arm Point and Onslow had great difficulty in acquiring suitable software. Their distance from software publishing houses and the infrequent visits of support personnel limited opportunities for buying software to holiday periods or the use of mail-order catalogues. Without a suitable range of software to run on the computer, implementation of the technology was slow. Software updates were needed as the computer programme developed. The following section discusses other significant aspects of software for the computer education programme.

\section{The issue of software in the computer education programme}

Some software issues were only identified in the remote locations, particularly those schools which served traditional communities, where languages other than English are spoken, and English is spoken only in the school context. Most teachers commented so much available software was text-oriented and incongruent with students' reading abilities; they suggested that software for these schools should make greater use of the graphics, animation and sound capabilities of the computer, assisting those students with limited literacy skills. Incorporated within those facilities should be the use of characters, stories and items familiar to the people living within the remote communities.

Teachers from all schools desired software that could be adapted easily to make it more suitable for the needs of their students. Teachers in less traditional communities made fewer comments on the inappropriateness of the content of the software packages. Those adventure games which did not rely on previous knowledge or culturally-based knowledge such as nursery rhymes were predominantly used, as appropriate software was limited.

In each of the schools where the junior primary students had access to the computer, teachers reported a dearth of software suitable for the K-3 area. These teachers used the same few pieces of software regularly, and reported instances of student boredom.

The data also indicated that insufficient software was available for the frequent general use of the computer in classrooms. This finding was also evident in other Australian computer studies (Jennings et al., 1984; Commonwealth Schools Commission, 1983). Greater demands for software will occur with the widespread purchase and application of computer hardware in schools. Sufficient software needs to be made available to support such ventures. 
For an effective K-10 approach in computer education to be adopted, significantly more software, particularly in the K-3 area, needs to become available. A computer education programme will not develop without a range of appropriate software to suit the curriculum areas and Year levels. The continued recurrent use of the same software with the same students will lead to student and teacher boredom, and defeat the purpose of using computers as a learning tool.

\section{Employment of teaching strategies with the use of the computer}

Among the six schools, a variety of teaching techniques were adopted. Two patterns of use emerged from the study - one for avid users and one for infrequent users.

It was found that the more experienced computer operators tended to make more use of peer tutoring and small-group work, and integrated the computer into their class to support their existing programmes. Less experienced users used the computer as a fill-in between lessons or as a reward for good work, the latter usually resulting in inequitable access to the computer by students. The former approach was made by experienced staff who, often, developed it after in-servicing and through great personal effort to fully understand the capabilities and potential of the technology.

\section{Student responses to computer education}

All students observed in the study related in a positive and enthusiastic manner to the use of the computer. This is consistent with other studies of Aboriginal students using computers (Lovegrove, 1985). Where permitted, most students worked on the computer in their free time before and after school and during recess and lunch breaks. The type of software used did not deter their enthusiasm, although over-use of a single package was likely to eventually produce boredom. Otherwise, what was seemingly boring drill and practice software was greeted with as much enthusiasm as that shown over more exciting packages. When students were given a choice, 'Granny's Garden' and arcade games were frequently requested in most schools.

Adventure packages (such as 'Granny's Garden') tended to encourage more higher-order verbalizations than did drill and practice software. For example, group problem solving, divergent thinking, and discussions outlining reasons for choices occurred frequently, particularly when a small group worked together. Significantly more co-operation and other social skills occurred when students worked in small groups, or as a whole group with a peer leader. In the more traditional communities (Warburton), such discussions occurred with a mix of English and 
Wangai. As most of the teaching programmes within many of the more traditional communities focused on literacy, adventure software combined with small group work would presumably offer the best environment for language development.

Most students had little difficulty in operating the hardware and software. For example, the students at One Arm Point performed many of the software editing tasks normally done by teachers. Such proficient skills in operating both hardware and software clearly indicate an underestimation of student capabilities. Similar observations were reported by staff at Midvale with the pre-primary and junior primary students.

Student responses over the twelve-month period did not appear to change, and students seemed to be as motivated to use the computer at the end of the study as they were at its commencement.

\section{Teacher perceptions of student responses to computer education}

Due to limited and inconsistent access, most teachers in the six schools could not attribute improvements in academic performance to the computer. However, many observations were made that clearly identified the computer as the cause for some improvement in academic skills. This is consistent with most studies of Aboriginal students using computers in Australia (Fryer, 1985; Bowman, 1985). These teacher observations are discussed in this section.

Many teachers noted that students had a significantly longer concentration span when using the computer. They observed that students' typing skills increased dramatically with practice. Junior primary teachers reported that an alphabetic keyboard would assist students with this process in the junior years.

It was reported by the teacher that a change in a student's self-expectations had occurred because the student experienced success on the computer.

Teachers also reported changing their expectations of students after seeing what they were capable of doing on the computer. An example cited was at Rangeway, where the lower ability group which was normally plannedfor separately, had used mainstream spelling lists, and when tested with the whole group had performed equally well, a gain from 20 per cent correct to 80 per cent. Many other teachers reported improvements in spelling, mental mathematics and reading, and attributed these to the use of the computer. Studies conducted with American Indian students illustrated that significant academic gains were possible through intensive CAI (Edeburn and Jacobi, 1984; Edeburn, 1985; Fletcher and Sawyers, 1984; Hakes, 1981). These studies have tended to suggest that where 
students are given consistent and long-term access to the computer, such gains may also be possible in school contexts for Aboriginal students.

These findings indicate that teacher expectations of student performances are changed by using the computer. Low expectations of Aboriginal students are reported in many schools. Where this type of 'self-fulfilling prophecy' can be broken down; students will have more chances of success. If the computer is seen to assist in this breakdown, then effective implementation of computers is indeed vital, as these benefits are only achievable if student access is maintained.

\section{The community's perceptions of computer education within the school}

Throughout the study, community perceptions were difficult to collect. The four one-week visits in each of the schools in group A and the two one-week visits in each of the schools in group B were not sufficient to acquire a comprehensive understanding of the community's perceptions. Most perceptions were acquired through the AEWs, Aboriginal Liaison Officers (ALO), community advisers and the school staff.

In many schools, there was little general community involvement. But, with the introduction of the computer into the school, a variety of contacts with the community occurred. Midvale and Rangeway shared their new acquisition with the community through a display at the Parents and Citizens Association meeting. One Arm Point and Onslow took this one step further and invited the community in for a computer night, where hands-on experience was encouraged. At Onslow, predominantly nonAboriginal community members attended while at One Arm Point a significant number of Aboriginal families attended. After such an introduction, further knowledge exchange happened at One Arm Point, where visitors into the school were given demonstrations on the use of the computer by the Principal. Immense interest was generated and where knowledge exchange had occurred positive community responses were forthcoming. Warburton and Halls Creek did not provide opportunities for the community to learn about the computer. A degree of apprehension was expressed by some community members in Warburton (traditional community); they were concerned that time spent using computers would be time away from learning the three 'Rs', and that the computer could be another 'basket weaving' activity introduced into the school.

Where AEW involvement in the programme occurred, significantly more knowledge interchange resulted. This was illustrated by the AEW in Onslow, who had invited community members to visit the school and make use of the computer facilities. Without the provision of a knowledge exchange (about the possible uses of computers within the school or community) a disparity may arise, as the information base normally held 
by the elders is passed on to the children and is not in keeping with the rules governing traditional communities. Where community people are hesitant about approaching the school, as happened in Halls Creek and Onslow, perhaps neutral territory could be used for computer related tasks, or the computer could be taken into the community for extended periods, so that elders could become familiar with its use. An initiative such as this could take place at the commencement of the programme. Such findings support the notion of a greater awareness by educators of the continuum from urban dispersed to traditional communities (National Aboriginal Education Committee categories; Willmott, 1981), and how adherence to traditional cultural norms is imperative within traditionally oriented communities and progressively less pronounced as communities become more Westernized.

\section{The continuity of the computer education program established in the school}

Of major risk to the established computer education programme is the area of provision for continuity, where students are unable to receive continued access to the computer after the current staff transfer. Many schools in the study experience massive staff changes every two years. Hence, many innovations introduced at a school may be lost after that time. Most significant is that of continuity. Each of the six schools in the study developed different mechanisms to address this concern for continuity.

The most common response was the drafting of a computer education policy. Where AEW involvement occurred in the computer education programme, the school generated some continuity. The stability of the AEW position, since AEWs are usually continuing members of the local Aboriginal community, ensures that the knowledge base for computer education skills - and a knowledge of what has happened previously remains in the school, even though staff turnover may be frequent. Similarly, a multi-level approach such as that adopted by Rangeway would help to ensure continuity.

The programmes most at risk are those of the kind operating in Halls Creek and One Arm Point. When skilled staff transfer out of the school they will take with them much of the expertise built up in the school over time. Without continuing skill in the school, new teachers are unlikely to make effective use of computers, and students will be denied access. Continuity of the programme is essential if equitable long-term access is to be achieved in schools with significant numbers of Aboriginal students. The more remote the location, the greater the difficulties, and consequently, the students attending such schools, when compared with their counterparts in the city, can be significantly disadvantaged. 


\section{Summary}

This cross-cultural study has examined the contextual factors surrounding implementation. After careful analysis, staff perceptions, support structures within the school, environmental constraints, teaching strategies, and student and community responses to the introduction of computers were presented and discussed in this paper.

Each of these factors affected student access to the computers. Where implementation was hampered or interrupted due to a lack of provision for continuity, inequitable access by students resulted. The above constraints could be so pronounced that the computer education programme could even be aborted leaving students with no access to computers.

The study's findings clearly show that Aboriginal students' access to computers in their schools may be haphazard and certainly not guaranteed year after year. A history of staff turnover, new graduates with limited computer expertise and inappropriate software in these schools, further reduced the opportunities and thus, increased educational disadvantage, for Aboriginal students. The findings suggest that unless specific provisions are made to enhance the implementation of computer education into schools with substantial Aboriginal enrolments, especially in remote locations, Aboriginal students may not be able to share the increasing advantages gained through access to computers in education.

\section{References}

Bowman, N.F. (1985). The Role of Computers in Aboriginal Education. Interim report to the School Commission, Canberra. (unpublished)

Commonwealth Schools Commission (1983). Teaching, Learning and Computers. Report of the National Advisory Committee on Computers in Schools. Union Offset, Canberra.

Edeburn, C.E. \& Jacobi, C. (1984). Computer Assisted Instruction for Native American Students. Paper presented at the Annual Northern Rocky Mountain Educational Research Association meeting, October. ERIC Document, ED 252336.

Edeburn, C. (1985). Statistically Speaking. The Computing Teacher, April, 1216.

Education Department of W.A., (1986). School Enrolment Statistics. (unpublished).

Fletcher, J. D. \& Sawyer, T. E. (1984). Computer-Aided Instruction in Education, Basic for Indian Students. Proceedings of the Indian Education Conference. Dept. of Education, Washington DC. ERIC Document ED 247053. 
Fryer, M. (1985). APPEP Computer Assisted Learning Study. Interim report on the Aboriginal Post-Primary Education Project, Research Unit, Education Department of South Australia, Adelaide (unpublished).

Hakes, J. A. (1981). Computer Storytelling: Mathematics for Pueblo Indian Upper Elementary Level Students. Final report. National Institute of Education, National Science Foundation. ERIC Document ED 251888.

Jennings, P. J. \& Bradley, J. (1984). Review of the Commonwealth Computer Education Program in Government Schools in Western Australia. Institute of Social Programme Evaluation, Murdoch University, Western Australia. (unpublished).

Willmott, E. (1981). The Culture of Literacy. In B. Menary, (ed.) Aborigines and Schooling. Adelaide, SA: Griffin Press, pp. 4-19.

Author: Marilyn Fleer lectures in the School of Education at the Canberra College of Advanced Education, PO Box 1, Belconnen, ACT 2616.

Please cite as: Fleer, M. (1989). A cross-cultural study of the implementation of microcomputers into schools. Australian Journal of Educational Technology, 5(1), 1-13. http: / / www.ascilite.org.au/ajet/ ajet5 / fleer.html 